\title{
SELEÇÃO DE TECNOLOGIAS DIGITAIS PARA A GERÊNCIA DE PROJETOS EM DISCIPLINAS DE PROJETO INTEGRADO
}

\author{
Danilo Almeida Felipe* \\ Tânia Saraiva de Melo Pinheiro ${ }^{* *}$
}

\begin{abstract}
Resumo: A disciplina de Projeto Integrado estudada é um componente curricular de caráter interdisciplinar que visa relacionar as unidades do currículo entre si em e com a realidade profissional. Além da interlocução com outras disciplinas - seus conteúdos e docentes - temse equipes de alunos resolvendo problemas sociais reais, desenvolvendo projetos enquanto aprendem os conteúdos necessários para desenvolvê-los. Dificuldades em sua complexa condução levaram à constatação da importância de se utilizar métodos de gerenciamento de projetos, e posteriormente de se dispor de tecnologias digitais que as apoiassem. Este estudo teve o objetivo geral de selecionar tecnologias digitais online para apoiar a gerência dos projetos integrados. A metodologia adotada consistiu, inicialmente, da observação da prática pedagógica para identificar os requisitos necessários a serem atendidos pelas tecnologias, seguida da análise comparativa de ferramentas digitais gratuitas disponíveis, finalizando com sua configuração para uma nova turma de Projeto Integrado. A partir de princípios pedagógicos estabelecidos foram selecionadas duas ferramentas, sendo uma para gerência de projetos e, de forma complementar, outra para organização dos arquivos digitais manuseados. A análise dos resultados ainda é preliminar, porque o semestre letivo ainda está em andamento, mas já apontam para uma maior capacidade de acompanhamento do trabalho, por alunos e docentes envolvidos. Entretanto, já se observa a necessidade de se alocar mais tempo de aula para orientações tanto em gerência de projetos quando na ferramenta selecionada para este fim.
\end{abstract}

Palavras-chave: Projeto Integrado. Gerência de Projetos. Métodos Ágeis.

\section{Introdução}

Este estudo trata da seleção e configuração de tecnologias digitais online para auxiliar na condução de disciplinas de Projeto Integrado de um curso de graduação em Design Digital. Ele é um recorte de uma pesquisa longitudinal, do tipo intervenção pedagógica (DAMIANI, 2012), que visa sistematizar a prática pedagógica em disciplinas de Projeto Integrado do referido curso, em uma instituição pública de ensino superior.

Projeto Integrado (PI) é uma nomenclatura utilizada para variadas ações sociais e educacionais. $\mathrm{Na}$ área social, consistem de ações muitas vezes comunitárias, com propósitos habitacionais e ambientais. Na área educacional, objeto deste estudo, consiste de "uma

\footnotetext{
* Graduando do curso de Sistemas de Informação da Universidade Federal do Ceará, Campus Quixadá.

** Professora Adjunta da Universidade Federal do Ceará, Campus Quixadá.
} 


\section{\#tear}

estratégia pedagógica, de caráter interdisciplinar [...] no sentido da integração curricular" (SANTOS; BARRA, 2012, p. 2).

Especificamente no ensino superior, foram identificadas diferentes nomenclaturas, tendo-se adotado Projeto Integrado aquilo que a literatura denomina por Projeto Integrado, Projeto Integrador, Ateliê ou Oficina. Tais disciplinas são organizadas em torno de projetos assumidos preferencialmente por equipes de estudantes, orientados por um ou mais docentes, com fins de relacionar as unidades do currículo entre si e com a prática profissional real.

No curso de Design Digital estudado, existem quatro disciplinas obrigatórias denominadas Projeto Integrado (I, II, III e IV) ofertadas do terceiro ao sexto semestre. Em todas tem-se a elaboração de um projeto prático e interdisciplinar, mas com diferentes ênfases conforme variação das demais disciplinas do semestre. Neste estudo, foram consideradas as duas primeiras, PI I e PI II, que possuem maiores similaridades na metodologia projetual utilizada, ou seja, na metodologia de design utilizada no desenvolvimento dos projetos.

As duas disciplinas de PI estudadas gerenciam a realização de projetos em conjunto com todas as outras quatro disciplinas do mesmo semestre letivo. A complexitade da tarefa é ampliada pelo fato das equipes de estudantes trabalharem com problemas sociais de clientes e usuários reais. São projetos interdisciplinares e complexos. O intenso ritmo de trabalho demanda grande capacidade de planejamento e organização, e buscou-se na área de gerência de projetos orientações para superar as dificuldades vivenciadas na condução dos projetos.

Gerência, ou gerenciamento, de projetos consiste da arte de aplicar conhecimentos, habilidades, ferramentas e técnicas em atividades de projetos para que suas metas sejam alcançadas (PMI, 2013). O gerenciamento de projetos permite coordenar a realização de trabalhos complexos, e na literatura encontram-se diferentes guias e modelos para esse fim. Dentre eles, identificamos o PMBoK (PMI, 2013) como um dos mais renomados, mas ele é um guia extenso e um pouco burocrático, com procedimentos rígidos e grande volume de documentação, sendo inadequado para projetos de pequeno porte.

Para o desenvolvimento de produtos de software, área da qual faz parte o curso de Design Digital estudado, novas abordagens de gerenciamento de projetos se tornaram necessárias para trocar a burocrática documentação por maior agilidade em se fazer entregas parciais rápidas e frequentes, permitindo maior interação com o cliente durante o desenvolvimento (SOMMERVILLE, 2011). Em busca de novas abordagens, profissionais da área reunidos em um evento conhecido como Agile Manifesto (BECK et al., 2001) forneceram uma base filosófica para os denominados Métodos Ágeis, como o eXtreme Programming (XP), Scrum, Feature-Driven Development (FDD). 


\section{\#tear}

Para atender à disciplina de PI, selecionamos o método ágil Scrum, já utilizado na instituição e, principalmente, alvo de pesquisas em educação (BERTAGNOLLI; HUBLER; NICOLAO, 2011; DANTAS; SANTOS, 2016; PERSSON et al., 2011). Ele está sendo implantado aos poucos, em busca das adaptações necessárias à disciplina PI, em que se tem a elaboração de produtos digitais e estreita relação com o desenvolvimento de software.

Como forma monitorar o andamento dos projetos - suas atividades, responsáveis e prazos - a literatura do Scrum orienta para o uso de painéis fixados em paredes, com post-its indicando atividades a fazer, em andamento ou concluídas. Os painéis são muito bons em empresas, onde as equipes passam todas as suas horas de trabalho no mesmo ambiente. Mas com estudantes é diferente: muito do trabalho é desenvolvido em locais e horários diferentes da sala de aula, fazendo com que não tenham acesso aos painéis com o planejamento.

Assim, em adição ao método de gerência de projetos, era preciso dispor de tecnologias digitais online que dessem suporte à documentação associada ao método. Além de se alinharem com o Scrum, elas deveriam possibilitar que, a todo momento, estudantes e docentes tivessem acesso aos materiais produzidos e ao planejamento do trabalho.

A partir desta problemática, o objetivo geral deste estudo consistiu em selecionar ferramentas digitais online que dessem suporte para a implantação do Scrum em disciplinas de Projeto Integrado. Foram inicialmente identificados os requisitos necessários das tecnologias a serem propostas, por meio da observação da prática. Em seguida, foram selecionadas as ferramentas necessárias, que deveriam atender a princípios educacionais estabelecidos. Por fim, as ferramentas foram configuradas para uso por uma turma nova de Projeto Integrado.

\section{A disciplina Projeto Integrado}

Projeto Integrado, enquanto atividade acadêmica, consiste de "uma estratégia pedagógica, de caráter interdisciplinar [...] no sentido da integração curricular" (SANTOS; BARRA, 2012, p. 2). Por meio de levantamento bibliográfico a respeito de projetos integrados, identificou-se que não há padronização de sua nomenclatura, podendo ser encontrada como: Projeto Integrado, Projeto Integrador, Ateliê, ou Oficina. Neste estudo, é adotada a primeira opção, Projeto Integrado (PI).

A pedagogia do trabalho com projetos integrados no ensino superior é bem caracterizada por Schon (2000), ao tratar de Ateliês de Projetos Arquitetônicos como Modelo Educacional como uma epistemologia da prática baseada na ação-reflexão. Qualificando arquitetos como designers, o autor explica que "ateliês, em geral, são organizados em torno de projetos gerenciáveis de design, assumidos individual ou coletivamente, mais ou menos 
padronizados de forma similar a projetos dirados da prática real.” (SCHON, 2000, p. 45, grifo nosso). Grifou-se a necessidade de se conseguir gerenciar os projetos definidos.

Para Severo (2018, p. 33), atividades integradoras são propostas que visam a “interdisciplinaridade do currículo", com fins de relacionar as unidades do currículo (disciplinas) entre si e com a realidade. A integração aqui está relacionada à "associação e síntese desses diversos conteúdos disciplinares" (RODRIGUES, 2017, p. 48).

Uma análise aprofundada da literatura revelou diferentes formas de se proceder a integração das disciplinas envolvidas, o que conduziu os pesquisadores à necessidade de estabelecer uma tipologia das diferentes formas de integração curricular. Como ponto de partida, foi tomado que a integração pode ocorrer de forma horizontal ou vertical (IGLÉSIAS; BOLELLA, 2015; JÁCOME; VIEIRA, 2013). A tipologia final é sumarizada no Quadro 1.

$\mathrm{Na}$ integração horizontal, PI faz interlocução com outras disciplinas do mesmo período letivo, e alunos desenvolvem projetos enquanto aprendem os conteúdos que os fundamentam. Como o levantamento bibliográfico realizado, estabeleceram-se dois subtipos, assim nomeados: (1) horizontal-curricular quando é obrigatória; ou (2) horizontal-livre, quando professores de um único semestre promovem projetos interdisciplinares de forma espontânea, sem a obrigatoriedade da existência de uma disciplina do tipo PI.

$\mathrm{Na}$ integração vertical, os projetos aplicam conteúdos já aprendidos por alunos em semestres anteriores, e também estabeleceram-se dois subtipos: (1) vertical-curricular, quando há uma disciplina de PI, podendo esta ter um ou mais docentes alocados; (2) vertical-livre quando há um evento acadêmico, independente de oferta de disciplinas.

De forma complementar, classificaram-se as formas da interlocução entre diferentes docentes, e se ela ocorre internamente ou em uma discipilina, ou externamente a disciplinas. Foi com certa surpresa que se identificou uma terceira situação: em que não está prevista a interlocução entre diferentes docentes (tipo vertical-curricular-não prevista).

A tipologia foi decisiva para que se compreendesse porque havia tanta dificuldade no gerenciamento dos projetos das disciplinas de PI estudadas, dificuldades que haviam conduzido seu corpo docente à decisão de se implantar práticas de gerenciamento de projetos. Identificou-se que este estudo trata de um caso de PI do tipo integração horizontal-curricularexterna, o qual se mostra o mais desafiador de todos porque:

a) enquanto a integração horizontal-livre possibilita dimensionar a amplitudade a participação de uma ou outra disciplina, por não ser uma exigência normativa do projeto do curso, na horizontal-curricular não há essas possibilidades, demandando grande esforço de integração dos planejamentos didáticos envolvidos; 


\section{\#tear}

b) enquanto na integração vertical tem-se equipes com estudantes que já concluíram o estudo dos conteúdos demandados pelos projetos, na integração horizontal os conteúdos demandados são aprendidos de forma simultânea enquanto o projeto evolui. Tal situação, novamente, impõe o desafio de se conseguir sincronização de todas as atividades das disciplinas envolvidas;

c) enquanto na integração horizontal-curricular-interna professores das diferentes áreas compartilham tempos e espaços com turma, com horizontal-curricular-interna não está previsto se encontrarem em sala de aula; pode ocorrer, inclusive, que professores de disciplinas relacionadas estejam indisponíveis nos horários do Projeto Integrado por estarem alocados em outras turmas naquele horário.

Quadro 1 - Tipologia de integração interdisciplinar e respectivos exemplos.

\begin{tabular}{|c|c|c|}
\hline \multicolumn{3}{|c|}{ HORIZONTAL - Integração com disciplinas do mesmo período letivo } \\
\hline \multicolumn{3}{|c|}{ CURRICULAR - Integração obrigatória, prevista em currículo } \\
\hline & INTERNA - Grupo de docentes alocados em PI & Rodrigues e Lima (2017) \\
\hline & $\begin{array}{l}\text { EXTERNA - Um docente em PI, e demais docentes em suas } \\
\text { respectivas disciplinas }\end{array}$ & Monteiro e Sampaio (2017) \\
\hline \multicolumn{3}{|c|}{ LIVRE - Integração dependente da participação espontânea de docentes } \\
\hline & $\begin{array}{c}\text { EXTERNA - Docentes alocados em suas respectivas } \\
\text { disciplinas. Não há disciplina PI }\end{array}$ & Holanda e Bairral (2017) \\
\hline \multicolumn{3}{|c|}{ VERTICAL - Integração com conteúdos de disciplinas de semestres anteriores } \\
\hline \multicolumn{3}{|c|}{ CURRICULAR - Integração obrigatória, prevista em currículo } \\
\hline & INTERNA - Grupo de docentes alocados em PI & Coutinho et al. (2016) \\
\hline & NÃO PREVISTA - Um único docente alocado em PI & Sousa et al. (2017) \\
\hline \multicolumn{3}{|c|}{ LIVRE - Integração dependente de participação espontânea de docentes } \\
\hline & $\begin{array}{l}\text { EXTERNA - Evento acadêmico independente de disciplinas } \\
\text { Não há alocação formal }\end{array}$ & Batistello et al. (2016) \\
\hline
\end{tabular}

Fonte: Elaborado pelos autores.

Schon (2000, p. 79) expressa a complexidade do trabalho com projetos integrados definindo o que chama de "paradoxo": o aluno mergulha "na atividade de projetar, tentando, desde o início, fazer o que ainda não sabe como fazer, de modo a ganhar o tipo de experiência que o ajudará a aprender o que significa o projeto".

A partir da turma de PI 1 do primeiro semestre de 2017, denominado 2017.1, se deu mais atenção à sistematizar as diversas tarefas a serem cumpridas, seus prazos, e se começou a usar compartilhamento de arquivos online para dar acesso mais frequente às produções das 


\section{\#tear}

equipes. Começava ali a busca por soluções que proporcionassem melhor gerência dos projetos desenvolvidos.

Naquele mesmo semestre 2017.1, o professor de PI III começava a adotar o Scrum, e com suporte de uma ferramenta digital online. As equipes de PI III relataram ter trabalhado com mais tranquilidade, mas não foi possível saber se o resultado foi satisfatório apenas por causa da melhor gerência de projetos e uso de ferramentas, ou porque os alunos já estavam mais acostumados com a dinâmica desse tipo de disciplina por já estarem no terceiro PI.

Entendeu-se que a avaliação do impacto da implantação da gerência de projetos só poderia ser realizada em uma turma iniciante, e o desafio passou a ser implantar soluções similares no PI I do semestre seguinte (2018.1). Como primeiro passo, buscou-se o estudo teórico que subsidiasse a investigação da real adequabilidade do Scrum para as disciplinas.

\section{Gerência de Projetos Integrados com Scrum}

Projetos são ações futuras planejadas para a criação de produtos, serviços ou resultados exclusivos. Quando deixam de ser exclusivos, se tornam processos. Projetos chegam ao seu final quando as metas são atingidas, ou motivo de força maior como o final do prazo. Sendo exclusivos, configuram-se de esforços e resultados singulares e distintos que, por sua vez, os tornam complexos e difíceis de condução (PMI, 2013).

A arte de aplicar conhecimentos, habilidades, ferramentas e técnicas em atividades de projetos para que suas metas sejam alcançadas é denominada gerência ou gerenciamento de projetos (PMI, 2013).

O Scrum é um framework para gerenciamento de projetos, com raízes no Agile Manifesto organizado por Beck et al. (2001). Ele surgiu em resposta a problemas decorrentes de modos rígidos e burocráticos de conduzir projetos de software, que na grande maioria das vezes resultavam em não cumprimento de prazos, orçamentos e inflexibilidade a mudanças para atender reais demandas dos usuários.

A denominação framework significa que é um arcabouço metodológico, e não uma metodologia, no sentido de que se trata de uma estrutura para orientar o trabalho e não uma receita a ser seguida. Ele prevê a integração com técnicas externas (SCHWABER; SUTHERLAND, 2016), além de ser multidisciplinar e não utilizado apenas no campo do desenvolvimento de software da computação. Entretanto, uma vez que a palavra framework ainda não é muito habitual na área educacional, este artigo utilizará alternadamente a palavra método para se referir ao Scrum. 


\section{\#tear}

A flexibilidade do Scrum sinaliza sua aplicabilidade às disciplinas de PI, em que projetos são continuamente elaborados de forma incremental, à medida que os alunos aprendem novos conhecimentos nas demais disciplinas do semestre. Adicionalmente, ao aceitar processos e técnicas externas, facilmente se tem conseguido integrar com as demais metodologias utilizadas pelos alunos: a metodologia projetual utilizada, específica da área de Design, e metodologia do trabalho científico.

Rocha, Sabino e Acipreste (2015, p. 15) reconhecem que, na educação, o Scrum revela-se "um arcabouço de técnicas e modelos para gerenciamento de projetos [...], indicando uma aprendizagem significativa que prepara o aluno para outras situações de sua vida.”. Os autores realizaram um estudo de caso da sua aplicação em uma disciplina de ensino médio profissionalizante, no qual relatam ser potencialmente adequado à promoção da aprendizagem, além de uma consequente preparação profissional.

O Scrum estabelece um processo de desenvolvimento iterativo e incremental, por entender que mesmo o desenvolvedor mais experiente aprende à medida que desenvolve o projeto. O Scrum organizam os times (equipes) e o trabalho em papéis, artefatos e cerimônias (SCHWABER; SUTHERLAND, 2016).

Os papéis que compõem um time Scrum são: Product Owner, um representante de partes interessadas de um produto a ser desenvolvido e seus desejos sobre ele; o Scrum Master, facilitador e aplicador das regras do Scrum e visto como um gerente do projeto; e Equipe de Desenvolvimento, conjunto de profissionais que trabalham na construção de um produto a ser desenvolvido.

Os artefatos definidos são o Product Backlog e o Sprint Backlog, que equivalem a listas dos requisitos esperados para o produto - simplificadamente: listas de tarefas.

Enquanto o Product Backlog contém uma lista completa de todos os requisitos já identificados, o Sprint Backlog contém o subconjunto selecionado para ciclos de trabalho (Sprint), e recebe mais detalhamento. As listas estão em constante evolução, e seus itens são ordenados por prioridade de desenvolvimento, possuindo atributos de descrição, ordem, valor e estimativa da carga de trabalho necessária.

Por fim, tem-se as cerimônias, em número de cinco: Sprints, Reunião de Planejamento, Reuniões Diárias, Reuniões de Revisão, Reuniões de Retrospectiva. Todo o trabalho é organizado a partir de "ciclos" de tempo pré-determinados e denominados Sprints.

Reuniões de Planejamento ocorrem no início de cada ciclo (Sprint), quando as equipes (time Scrum) se reúnem para definir a lista de tarefas a ser cumprida (Sprint Backlog), dentre o conjunto completo conhecido (Product Backlog). Os itens são detalhados e priorizados. 
Durante o período da Sprint $^{1}$, há a Reunião Diária com duração de até quinze minutos para discussões sobre o que foi feito no dia anterior, o que será feito no dia e se existe algum impedimento para concluir a Sprint (SCHWABER; SUTHERLAND, 2016).

O final da Sprint é marcado por duas cerimônias: uma apresentação pública (Revisão da Sprint), seguida de uma auto-avaliação pela equipe (Retrospectiva da Sprint). A Revisão da Sprint é uma reunião informal em que o time Scrum apresenta a evolução do produto às partes interessadas (Stakeholders) visando obter feedback quanto à evolução do que está sendo entregue. Encerrada essa apresentação, a Retrospectiva da Sprint é o evento (cerimônia) de autoavaliação do time Scrum, para discussão e implantação de melhorias no processo; (SCHWABER; SUTHERLAND, 2016).

Observando as disciplinas estudadas na perspectiva do Scrum, passou-se a compreender mais claramente o que significa o fato do Scrum ser uma estrutura de trabalho flexível (framework) e não uma metodologia a ser rigidamente seguida. Foi relativamente fácil aplicar seus papéis, artefatos e cerimônias à realidade das disciplinas.

Por exemplo, se conseguiu ver que as disciplinas já estavam planejadas em seis ciclos de trabalho (Sprints) com cerca de três semanas cada, que terminavam com apresentações (Revisão da Sprint) de, respectivamente: (1) briefing preliminar; (2) protótipos iniciais; (3) pré-banca, com a participação dos demais professores do semestre (stakeholders); (4) protótipos quase finais; (5) banca final avaliadora; (6) entregas e discussão final na turma.

Se conseguiu, também, identificar caminhos para os alunos não mais se "perderem" em meio a tantas tarefas: era preciso listar/documentar TODAS as tarefas a serem realizadas (Product Backlog), organizando-as cronologicamente nos ciclos de trabalho (Sprints). Os alunos também foram orientados a se reunir no início de cada ciclo para planejá-lo detalhadamente (Planejamento da Sprint), e dar mais atenção aos feedbacks recebidos nas apresentações realizadas (Revisão da Sprint).

Em busca de aplicar o conceito de Reunião Diária, foi solicitado às equipes que, ao serem formadas, já informassem dois horários de reunião extraclasse ao longo da semana que totalizassem um mínimo de seis horas semanais. Foi uma carga horária estimada para planejamentos e execução conjunta do trabalho e também o acontecimento da Reunião Diária. Com o horário pré-definido desde o momento da formação da equipe, inesperadamente foi resolvido um dos maiores geradores de conflitos: escolher horários para trabalhar juntos.

\footnotetext{
${ }^{1}$ A palavra Sprint é traduzida como arrancada, ou corrida muito rápida, o que a faz ser utilizada prioritariamente no feminino.
} 


\section{\#tear}

Para registrar o gerenciamento com projetos - suas atividades, responsáveis e prazos a literatura contendo casos de uso do Scrum fala muito do uso de painéis fixados em paredes, com post-its indicando atividades a fazer, em andamento ou concluídas. A Figura 1 ilutra um exemplo encontrado em Bertagnolli, Hubler e Nicolao (2012).

Figura 1 - Modelo de Painel Scrum

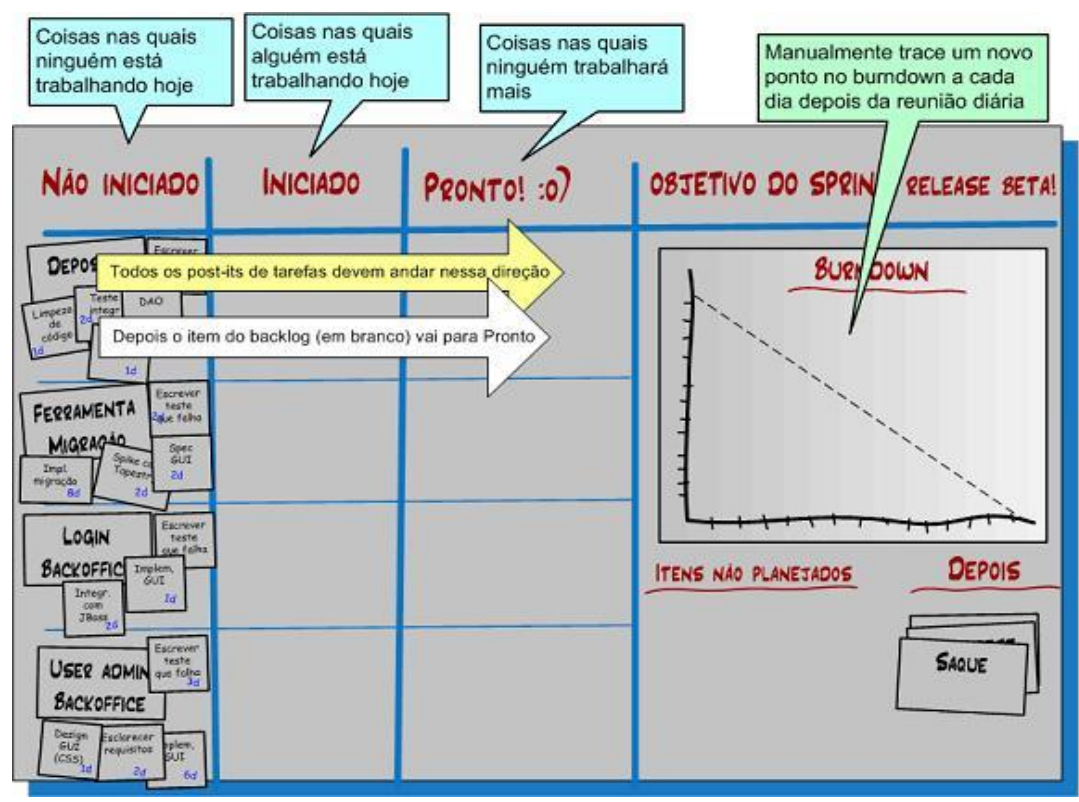

Fonte: Bertagnolli, Hubler e Nicolao (2012).

Os painéis em paredes são muito bons em empresas, onde as equipes passam todas as suas horas de trabalho no mesmo ambiente, mas com estudantes é diferente: muito do trabalho é desenvolvido em horários e locais diferentes da sala de aula, fazendo com que os alunos não tenham acesso justamente ao mapa do seu planejamento.

Apesar do grande uso de painéis, praticantes do Scrum também utilizam ferramentas online, em especial quando a equipe de desenvolvimento não trabalha em um mesmo ambiente físico. Desta forma, é vasta a oferta de soluções digitais online, a este estudo coube selecionar aquela que julgasse mais compatível tanto ao próprio Scrum quanto às especificidades da disciplina em que seria empregada.

\section{Seleção de tecnologias digitais: princípios e percurso metodológico}

Este estudo consiste de um recorte de uma pesquisa longitudinal, do tipo intervenção pedagógica (DAMIANI, 2012), que visa sistematizar a prática pedagógica em disciplinas de Projeto Integrado (PI) de um curso de graduação na área de Design, em uma instituição 
pública de ensino superior. Especificamente, trata da selação e implantação de tecnologias digitais para apoiar a gerência de projetos em disciplinas de Projeto Integrado (PI).

A introdução de tecnologia com fins educacionais nas disciplinas de Projeto Integrado do curso estudado pautou-se em dois princípios: (1) adoção de princípios do ensino híbrido, ou blended learning (BONK; GRAHAM, 2006); (2) visão de que ensinar com qualidade não depende apenas de tecnologias (MORAN et al., 2000, p. 12), sendo necessário que se tenha clareza do benefício adicional que se espera delas (BORGES NETO, 1998).

A justificativa para a adoção da perspectiva do ensino híbrido, ou semipresencial, se pauta na trajetória política do emprego das tecnologias de informação e comunicação na educação brasileira, resumida a seguir a partir de Pinheiro et al. (2014).

A narrativa das autoras começa no ano de 1995, quando a Secretaria Especial de Educação a Distância (SEED/MEC) foi criada com a atribuição de buscar "inovações tecnológicas e metodológicas para melhoria da qualidade da educação no Brasil" (BRASIL, 2006 apud PINHEIRO et al., 2014, p. 3). Computadores começaram a chegar às escolas.

No ano seguinte, ocorre a abertura comercial da internet e, em 1997, foi criado o Programa Nacional de Informática na Educação (Proinfo) para coordenar as ações nesta temática. Visando resolver o pouco uso dos já equipamentos implantados observados na época, a SEED passou a utilizar a infraestrutura de comunicação instalada para formar professores no uso das tecnologias com fins pedagógicos, "movendo o foco de discussões governamentais da Tecnologia Educacional (TecEdu) para a Educação a Distância (EaD)" (PINHEIRO et al., 2014, p. 3).

Como importante marco das políticas públicas para fomentar o uso de tecnologias educacionais no ensino superior, em 2004 foi instituída a graduação na modalidade semipresencial no país. O ato visava incentivar o uso de Tecnologias Educacionais no ensino superior, como condição necessária para se preparar docentes para atuar no iminente início da graduação a semipresencial.

Apesar de a portaria tratar de substituição de até $20 \%$ da carga horária presencial de cursos presenciais por atividades a distância, Pinheiro et al. (2014) observam que também existe o ensino semipresencial, ou híbrido, mesmo sem compensação de carga horária: quando se utilizam pedagogias similares à $\mathrm{EaD}$ em tempo adicional ao da sala de aula.

Finalizando esta revisão histórica, foi estabelecido que este estudo adotará a perspectiva do ensino híbrido/semipresencial, em contrapartida à perspectiva clássica de uso de computadores em escolas. O que muda? Ao se falar de computadores em escolas, a literatura aborda prioritariamente seu uso em tempo de sala de aula. As referências ao uso 


\section{\#tear}

extraclasse enfatizam sua aplicação e fixação de conteúdos por parte do aluno, ou realização de tarefas de casa, sem destaque à mediação pedagógica com a participação do docente.

A postura do ensino híbrido foi incluída, portanto, por se reconhecer a importância da mediação docente seja no presencial ou nas soluções online a serem implantadas. Tal definição é decisiva para especificar que a introdução de tecnologias deverá, necessariamente, prover meios que possibilitem a mediação pelos docentes.

Quanto à visão de que ensinar com qualidade não depende apenas de tecnologias, sendo necessário que se tenha clareza do benefício adicional que se espera delas, desperta a atenção para que a introdução de qualquer material instrucional, ou de qualquer nova intervenção pedagógica, não ocorra apenas porque "todos usam", ou "porque é tendência". A partir destes princípios, estabeleceu-se que uma a tecnologia educacional a ser introduzida teria a finalidade de melhorar o trabalho das equipes de Projeto Integrado nos seguintes aspectos:

a) organização de arquivos - possibilitar que o vasto conjunto de arquivos manuseados pelas equipes estivessem devidamente organizados e compartilhados entre seus membros e com os docentes;

b) gerenciamento de projetos - dispor de uma ferramenta online de gerenciamento de projetos, alinhada com as orientações do Scrum, o método escolhido.

Este estudo foi iniciado com o segundo semestre letivo de 2017, aqui denominado 2017.2, com observação não-participante (LAKATOS; MARCONI, 2010) da prática pedagógica visando identificar os requisitos necessários das ferramentas a serem propostas. Uma vez por semana, por cerca de dois meses, realizaram-se observações em uma turma de PI II, fazendo-se registros em diário de campo. Havia dezenove alunos divididos em quatro equipes, orientados por uma professora.

A seleção das ferramentas foi realizada logo após o término do semestre 2017.2, e já estava disponível para implantação na turma de PI I do semestre 2018.1. O procedimento de seleção consistiu de ampla pesquisa por ferramentas gratuitas de gerência de projetos e tabulação de suas características de forma a identificar qual a mais adequada à disciplina, conforme técnica para comparação de artefatos digitais descrita em Wazlawick (2014).

$\mathrm{Na}$ sequência, houve preparação das ferramentas selecionadas. A instalação e a configuração ocorreram após o final do recesso escolar, e os alunos começaram a utilizar já a partir do primeiro dia de aulas do semestre letivo seguinte (2018.1). Foi configurada para uso por uma turma de PI I, com precisamente cinquenta alunos divididos em nove equipes, e 


\section{\#tear}

conduzida por dois docentes. Neste caso, o número de docentes foi definido pelo tamanho da turma, de forma a ampliar a capacidade de atendimento às equipes, e não por suas especializações.

\section{Seleção de tecnologias digitais para gerência de Projetos Integrados}

Visando identificar os requisitos necessários às tecnologias digitais a serem selecionadas, procedeu-se uma observação não participante em uma turma de PI II do semestre letivo 2017.2 em uma turma de dezenove alunos divididos em quatro equipes, orientados por uma professora.

Por cerca de dois meses, uma vez por semana se observou a prática em sala de aula e, entre uma aula e outra, os pesquisadores se reuniam para analisar a prática. Identificou-se que a professora já havia começado a usar uma ferramenta de organização de arquivos escolhida pela turma, o Google Drive. Para gerência de projetos usava uma outra denominada Trello.

Sobre a seleção de ferramenta para organizar arquivos, os próprios fizeram a escolha dentre duas conhecidas: Dropbox e Google Drive. O Google Drive foi a escolhida por permitir: diferentes formas de compartilhamento, edição online e, no caso de textos, possibilidade da professora corrigir material online.

Uma vez definida a ferramenta, cada equipe organizou seus arquivos como preferia e, ao final do semestre, as equipes reunidas elaboraram uma organização de referência a ser proposta a turmas de PI posteriores. O Quadro 2 ilustra a organização final: o símbolo “/” indica que são pastas/subpastas e, sem ele, indicam-se arquivos. A numeração das pastas da raiz possibilitou ordenar os materiais de forma similar à sequência prevista no cronograma.

Quadro 2 - Referência para organização dos arquivos das equipes

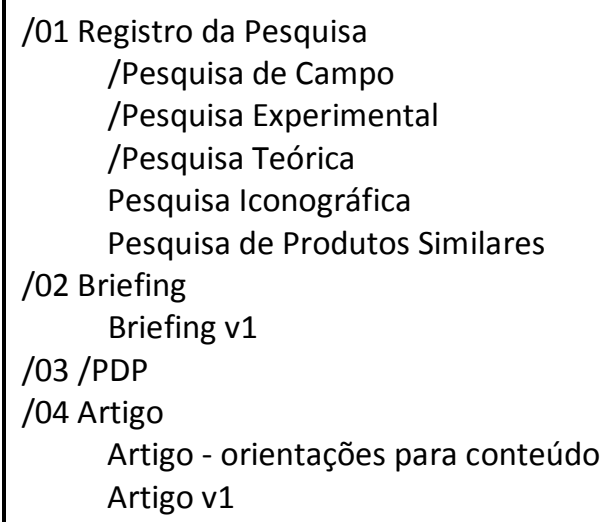

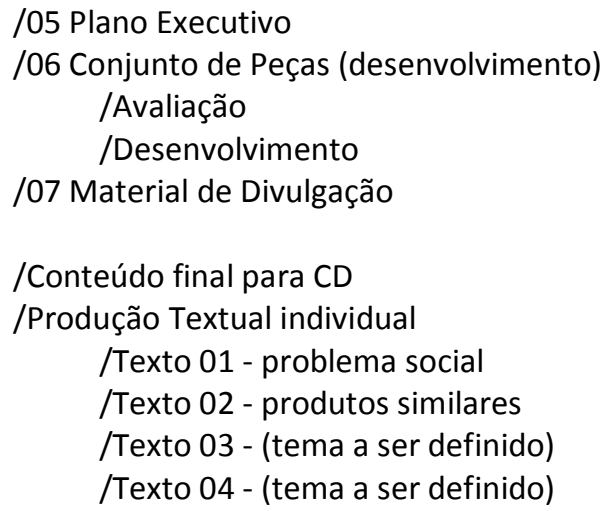

Fonte: Organizado pelos autores. 


\section{\#tear}

Quanto à seleção de ferramentas de gerência de projetos, a observação já revelou que o Trello não era suficiente para gerenciar adequadamente o projetos, mas ainda não se sabia precisar o motivo da limitação. Esta ferramenta havia sido escolhida por indicação de outros professores da instituição.

Partiu-se então para uma análise de variadas ferramentas, incluindo o próprio Trello. Dentre as soluções que foram analisadas estão: Trello, Zube.io, Taiga, MeuScrum, MyScrumHalf e MeisterTask. Todas são aplicações web, um modo encontrado para não se prender informações importantes apenas no ambiente de sala de aula. As duas primeiras, Trello e Zube.io, já eram utilizadas na instituição e as demais foram identificadas exaustivamente em mídias especializadas no gerenciamento ágil de projetos.

O Scrum sustenta-se em pilares de transparência, inspeção e adaptação (SCHWABER; SUTHERLAND, 2016), e esperava-se que a ferramenta selecionada suportasse esses pilares, o que ocorreria por meio do gerenciamento dos papéis, cerimônias e artefatos preestabelecidos no método. Conforme Quadro 3, as ferramentas Trello, Zube.io e MeisterTask não permitem o gerenciamento de papéis, e foram logo desconsideradas.

Quadro 3 - Atende ao Scrum?

\begin{tabular}{|c|c|c|c|}
\hline Ferramenta & $\begin{array}{c}\text { Gerenciamento de } \\
\text { papéis }\end{array}$ & $\begin{array}{c}\text { Demarcação } \\
\text { de Sprints } *\end{array}$ & $\begin{array}{c}\text { Gerenciamento } \\
\text { de artefatos }\end{array}$ \\
\hline Trello & não & não & não, apenas cards \\
\hline MeisterTask & não & não & apenas quadro de tarefas \\
\hline Zube.io & não & sim, com datas & $\operatorname{sim}$ \\
\hline MeuScrum & sim & sim, com datas & $\operatorname{sim}$ \\
\hline MyScrumHalf & $\operatorname{sim}$ & sim, com datas & $\operatorname{sim}$ \\
\hline Taiga & $\operatorname{sim}$ & sim, com datas & . \\
\hline
\end{tabular}

* Para gerenciamento das cerimônias, apenas o gerenciamento/demarcação das Sprints foi considerado. Fonte: Elaborado pelos autores.

Além da conformidade com o Scrum, as ferramentas deveriam atender aos seguintes requisitos que a disciplina Projeto Integrado necessitava:

a) permitir a criação de muitos projetos/times, pois havia grande possibilidade de muitos discentes matriculados no semestre 2018.1;

b) permitir entre 5 a 15 pessoas por time para possibilitar acompanhamento por todos os docentes das disciplinas envolvidas;

c) possibilitar alguma personalização, visando torná-la melhor configurável para eventuais demandas específicas da disciplina; 


\section{\#tear}

d) disponibilidade, que significa estar acessível e pronto para uso a qualquer momento.

O Quadro 4 resume a análise do quanto as ferramentas Taiga, MeuScrum e MyScrumHalf atendem a estes requisitos da disciplina Projeto Integrado I.

Quadro 4 - Análise para a disciplina.

\begin{tabular}{|c|c|c|c|c|}
\hline Ferramenta & $\begin{array}{c}\text { Criação de muitos } \\
\text { times }\end{array}$ & $\begin{array}{c}\text { Muitos membros por } \\
\text { time }\end{array}$ & Personalização & Disponibilidade \\
\hline MeuScrum & sim & sim & não & dependente do serviço \\
\hline MyScrumHalf & apenas paga & apenas paga & não & dependente do serviço \\
\hline Taiga & $\begin{array}{c}\text { sim, em nuvem } \\
\text { privada / do serviço } \\
\text { com projetos } \\
\text { públicos / versão } \\
\text { paga }\end{array}$ & $\begin{array}{c}\text { sim, em nuvem privada } \\
\text { / do serviço com } \\
\text { projetos públicos / } \\
\text { versão paga }\end{array}$ & $\begin{array}{c}\text { sim, ferramenta } \text { open- } \\
\text { source além de } \\
\text { fornecer nativamente } \\
\text { personalização }\end{array}$ & $\begin{array}{c}\text { em nuvem privada ou } \\
\text { dependente do serviço }\end{array}$ \\
\hline
\end{tabular}

Fonte: Elaborado pelos autores.

A ferramenta MeuScrum é totalmente gratuita para uso ilimitado, porém se teve muita dificuldade de compreendê-la, em especial quando comparada ao uso das demais. Adicionalmente, apesar de rica em funcionalidades, não permite personalizações. Sua disponibilidade é dependente do serviço fornecido pelo website da ferramenta em acordo com seus termos de uso. Seria um risco adotá-la, pois a qualquer momento poderia ficar offline.

A MyScrumHalf fornecia uso gratuito apenas para período de testes de apenas um mês, e com restrições, inviabilizando seu uso para o tempo compreendido de um semestre letivo.

A ferramenta Taiga foi inicialmente analisada em seu próprio website. A criação ilimitada de projetos e membros por projeto era permitida somente se os mesmos fossem públicos. A personalização é um pouco limitada e a disponibilidade dependente do serviço fornecido pelo website. No entanto, percebeu-se durante a análise que a ferramenta é de código-fonte aberto, com documentação acessível para que qualquer interessado possa instalar e usar sem restrições se instalado em equipamento próprio.

Por fim, optou-se por utilizar a ferramenta Taiga instalada e configurada em equipamento próprio para poder atender aos requisitos da disciplina Projeto Integrado. Além de ser gratuita, foi uma das premiadas como melhor ferramenta ágil ${ }^{2}$ e eleita uma das onze melhores ferramentas em gerenciamento de projetos $^{3}$, o que fortaleceu nossa escolha.

\footnotetext{
2 Best Agile Tools - Agile Awards 2015.

${ }^{3}$ PM Tools 2016 - opensource.com. 


\section{\#tear}

\section{Resultados e discussão}

A partir de princípios pedagógicos estabelecidos para o uso de tecnologias digitais como suporte à gerência de projetos em disciplinas de Projeto Integrado, foram selecionados dois tipos de ferramentas: uma de organização e gerência de arquivos, e uma para gerência de projetos pautada no arcabouço metodológico (framework) Scrum.

As ferramentas foram configuradas para uso pela turma de Projeto Integrado I, a se iniciar em março de 2018. Com os alunos divididos em nove equipes, foram criadas nove réplicas do modelo de organização de arquivos e de configuração da ferramenta Taiga que haviam sido definidos.

A organização prévia dos arquivos mostrou um efeito positivo não esperado: a própria estrutura, bem como os arquivos-modelo em seu conteúdo, estão servindo como um guia para as equipes visualizarem todas as etapas a serem cumpridas. Adicionalmente, os docentes puderam ser ativos no ambiente online, tendo-se observado que alguns textos foram avaliados de forma dialogada, com alunos e professores dialogando por meio do recurso de comentário disponíveis na edição online do Google Drive. A tecnologia está proporcionando melhores condições para se realizar avaliações de fato formativas.

A ferramenta de gerência de projetos Taiga foi implantada em um serviço de hospedagem $^{4}$ que oferece em um servidor dedicado de uso gratuito. Ela está acessível à turma de PI I por meio de link fornecido aos discentes e professores envolvidos.

Para ajustar a ferramenta à linguagem da disciplina e do Scrum, realizaram-se modificações em seus arquivos de tradução de linguagem. Por exemplo, modificou-se "História(s) de Usuário" - termo comumente utilizado para elaborar um requisito na Engenharia de Software - para "Item(ns) de Backlog".

As Figuras 3 e 4 ilustram a configuração e uso da Taiga, respectivamente. Na Figura 3, a lista Itens de Backlog mais ao centro mostra os itens ainda não alocadas em alguma Sprint. Nesta ilustração há apenas um item, porque os demais já foram distribuidos nas Sprints. À direita, se vê a lista de itens da primeira Sprint (Sprint Backlog), e se consegue visualizar o título de Sprints: S1. Definição do Problema Social a ser resolvido e S2. Definição dos primeiros requisitos da solução.

\footnotetext{
${ }^{4}$ Amazon Web Services 
Figura 3 - Uso da ferramenta Taiga por uma equipe

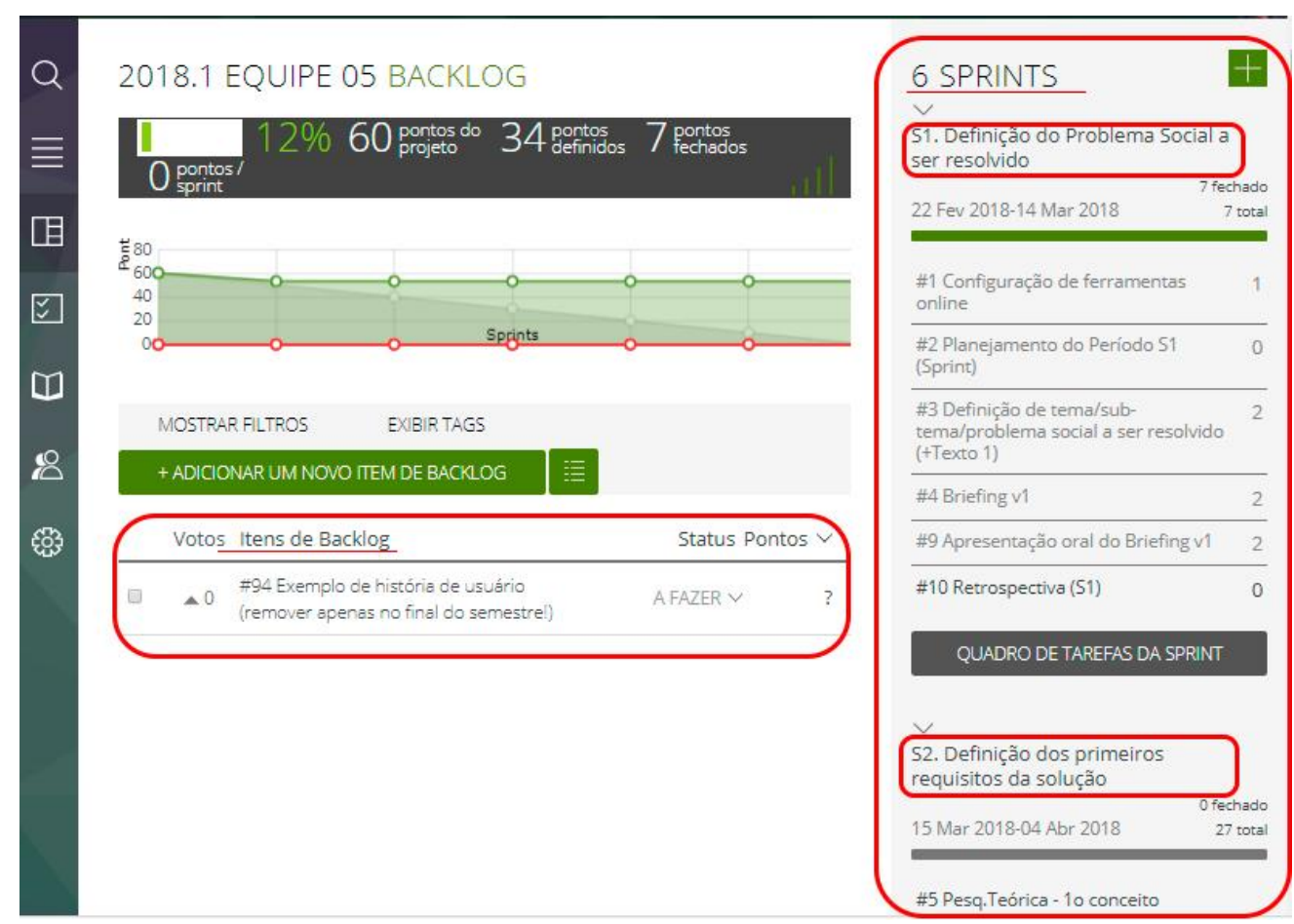

Fonte: Elaborada pelos autores.

A Figura 4 mostra a capacidade de acompanhamento dos trabalhos que a ferramenta proporciona. Há o registro de todas as atividades realizadas pelos membros das equipes.

Figura 4 - Registro de atividades de uma equipe

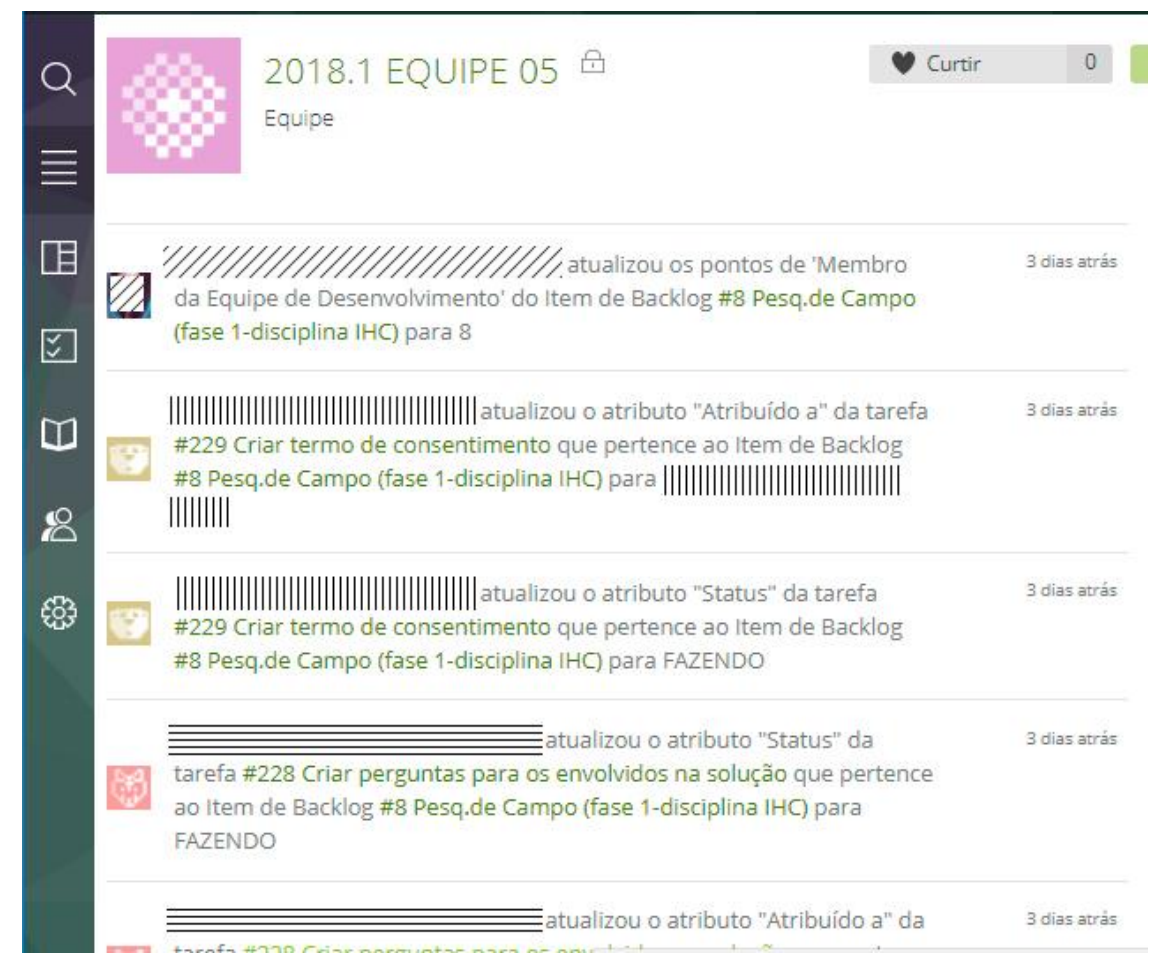

Fonte: Elaborada pelos autores. 
Com o semestre ainda em seu início, ainda não foi possível avaliar o impacto da implantação na realização dos projetos. Mas já se observa que agora se tem muito mais recursos para se planejar e acompanhar o andamento do trabalho, bem como interagir com membros da equipe e docentes.

\section{Considerações finais}

Dificuldades na condução de disciplinas de Projeto Integrado em um curso de graduação em Design Digital motivaram a utilização do Scrum, um método ágil para a gerência dos projetos. No decorrer do trabalho, e de forma acessória, também se definiu uma ferramenta para organização do vasto volume de arquivos digitais manuseado pelas equipes.

Trata-se de uma pesquisa cuja problemática começou a ser vivenciada no primeiro semestre letivo de 2017 (2017.1), chegando-se em 2017.2 com a necessidade de se escolher tecnologias digitais online que dessem suporte à gerência de projetos. Com este propósito, em 2017.2 se conduziu observações em uma turma de PI II, chegando-se aos requisitos necessários que as ferramentas deveriam atender.

A ferramenta Taiga para gerência de projetos foi selecionada e configurada com um para uso no semestre seguinte. Adicionalmente, também se observou a necessidade de uma solução para organizar os arquivos digitais de cada equipe, para o que se utilizou o Google Drive.

As contribuições deste estudo começaram a ser observadas já na implantação preliminar de elementos do Scrum na turma de Projeto II em 2017.2. A professora relata que praticamente todos os prazos das entregas parciais foram cumpridos. Os alunos, por sua vez, relatam que conduziram o trabalho com muito mais tranquilidade que na disciplina de Projeto I do semestre anterior. Ao final daquele semestre, todos os alunos foram aprovados e, o mais importante, os trabalhos foram muito elogiados na defesa final para uma banca avaliadora.

Com o semestre 2018.1 ainda em seu início, tem-se as tecnologias implantadas e em uso pelas turmas. Já se consegue observar contribuições da organização e compartilhamento de arquivos, na medida em que se tem docentes interagindo com os alunos por meio de comentários em arquivos online, o que atende aos princípios estabelecidos de se alcançar a mediação docente também online.

Entretanto, em relação ao uso da Taiga, há apenas indícios de resultados. Poucas equipes estão usando plenamente, e outras com muita dificuldade, mas ainda não foi possível avaliar plenamente as causas de uma ou outra situação. A hipótese é de que o tempo de aula destinado a orientações sobre gerência de projetos e uso da Taiga não foi suficiente. 


\title{
\#tear
}

O estudo não contou com limitações tecnológicas, pelo fato das tecnologias digitais já fazerem parte do cotidiano de todos os docentes e alunos do curso, e deste mesmo estar inserido em um Campus temático na área de computação.

Sua grande limitação tem sido conseguir tempo de aula para orientar os alunos no uso do Scrum e da ferramenta Taiga. A linguagem empregada pelo Scrum ainda não é corriqueira, o que dificulta ainda mais. Foi feita uma explanação na segunda aula do semestre, e a orientação posterior foi incluída apenas na nona aula. Mesmo as equipes mais interessadas no uso da ferramenta, acumularam muitas dúvidas tendo seu uso ficado comprometido. Desta forma, não se sabe se algumas dificuldades iniciais serem decorrentes de dificuldades de uso da Taiga, ou da própria gerência de projetos.

Uma vez que o aspecto tecnológico deste estudo foi concluído desde o início do semestre, a perspectiva do trabalho agora poderá se concentrar em seu aspecto humano: facilidade de uso, efetividade para se alcançar mais plenamente os objetivos pedagógicos das disciplinas de Projeto Integrado.

\section{SELECTION OF DIGITAL TECHNOLOGIES FOR PROJECT MANAGEMENT IN DISCIPLINES OF INTEGRATED PROJECT}

\begin{abstract}
The Integrated Project discipline is an interdisciplinary curricular component that aims to relate curriculum units, themselves and with professional reality. In addition to the connection with other disciplines - their contents and professors - it has teams of students solving real social problems, developing projects while they learn the necessary contents. Such complexity led to the importance of using project management methods, and to have digital technologies to support them. This study aimed to select online digital technologies to support the management of Integrated Projects. The methodology consisted initially of observing the pedagogical practice to identify the technologies requirements to be met, followed by the comparative analysis of available free digital tools, and finalizing with its configuration for a new class of Integrated Project. Based on established pedagogical principles, two tools were selected, one for project management and another for the organization of digital files handled. The analysis of the results is still preliminary because the semester is still in progress, but they point out to a better condition to monitor the work, by students and teachers involved. However, we have already observed the need to allocate more class time to orientations both in project management and in the tool selected for this purpose.
\end{abstract}

Keywords: Integrated Project. Project Management. Agile Methods. 


\section{\#tear}

\section{Referências}

BATISTELLO, P.; BALZAN, K. L.; PEREIRA, A. T. Cybis. Integração no ensino de arquitetura e urbanismo: experiências com ateliês verticais. Revista Projetar: Projeto e Percepção do Ambiente, Natal, v. 1, n. 3, p. 47-59, dez. 2016.

BECK, K. et al. Manifesto para Desenvolvimento Ágil de Software. [S.1]: Agile Manifesto, 2001. Disponível em: <http://agilemanifesto.org/iso/ptbr/manifesto.html>. Acesso em: 31 out. 2017.

BERTAGNOLLI, S. C.; HUBLER, P. N.; NICOLAO, M.. Fábrica de Objetos: um modelo para a qualificação profissional. \#Tear: Revista de Educação Ciência e Tecnologia, Canoas, v. 1, n. 2, 2012.

BONK, Curtis J.; GRAHAM, Charles R. The Handbook of Blended Learning: Global Perspectives, Local Designs. Nova Iorque: John Wiley \& Sons, 2006.

BORGES NETO, H.. Uma classificação sobre a utilização do computador pela escola. Revista Educação em Debate, Fortaleza, v. 1, n. 27, 1999.

BRASIL. Ministério da Educação. Desafios da educação a distância na formação de professores. Brasília: Secretaria de Educação a Distância, 2006.

COUTINHO, E. F.; GOMES, G. A. M.; JOSÉ, M. L. A. Applying design thinking in disciplines of systems development. In: EURO AMERICAN CONFERENCE ON TELEMATICS AND INFORMATION SYSTEMS (EATIS), 8., 2016, Cartagena. Anais... Cartagena: IEEE, 2016. DOI: 10.1109/EATIS.2016.7520123.

DANTAS, L. G. R.; SANTOS, A. M. C. Metodologia do design para web: uma proposta de unificação das metodologias Projeto E e Scrum. In: CONGRESSO BRASILEIRO DE PESQUISA E DESENVOLVIMENTO EM DESIGN, 12., 2016, São Paulo. Anais... São Paulo: Blusher Design, 2016. p. 1500-1512. DOI: 10.5151/despro-ped2016-0127.

DAMIANI, M. F. D. Sobre Pesquisas do Tipo Intervenção. In: ENCONTRO NACIONAL DE DIDÁTICA E PRÁTICAS DE ENSINO, 16., 2012, Campinas. Anais... Campinas: UNICAMP, 2012.

HOLANDA, A. C. A.; BAIRRAL, M. A. Possibilidades do E-Learning em Projetos Interdisciplinares no IFAC. In: Congresso Brasileiro de Informática na Educação, 6., 2017, Recife. Anais dos Workshops... Recife: SBC, 2017. p. 409-413. DOI: 10.5753/cbie.wcbie.2017.409.

IGLÉSIAS, A. G.; BOLLELA, V. R. B. Integração curricular: um desafio para os cursos de graduação da área da Saúde. Revista Medicina, Ribeirão Preto, v. 3, n. 48, p. 265-272, 2015. DOI: 10.11606/issn.2176-7262.v48i3p265-272.

JÁCOME, M. F. T.; VIEIRA, N. M. A interdisciplinaridade no ensino de projeto: a proposta pedagógica do projeto integrado no curso de arquitetura e urbanismo da UNP-Mossoró. In: SEMINÁRIO NACIONAL SOBRE ENSINO E PESQUISA EM PROJETO DE ARQUITETURA (PROJETAR), 6., 2013, Salvador. Anais... Salvador: FAU-UFBA, 2013. 


\section{\#tear}

LAKATOS, E.; MARCONI, M. A. Fundamentos da Metodologia Científica. 7. ed. São Paulo: Atlas, 2010.

MORAN, J. M. ; MASETTO, M. T.; BEHRENS, M. A. Novas tecnologias e mediação pedagógica. 6. ed. Campinas: Papirus, 2000.

MONTEIRO, I. T. M.; SAMPAIO, A. L. Trabalhando a diversidade e a inclusão social na disciplina de projeto integrado. In: WORKSHOP SOBRE ENSINO DE INTERAÇÃO HUMANO-COMPUTADOR (WEIHC), 2017, Florianópolis. Anais... Florianópolis: SBC, 2017.

PERSSON, Mia et al. On the Use of Scrum in Project Driven Higher Education. In: INTERNATIONAL CONFERENCE ON FRONTIERS IN EDUCATION: COMPUTER SCIENCE AND COMPUTER ENGINEERING (WORLDCOMP'11 - FECS'11), 11., 2011, Las Vegas. Anais... Las Vegas: Worldcomp, 2011. p. 1 - 6.

PINHEIRO, T. S. M.; PINHEIRO; A. C. M. ; ROLIM, G. F. Pedagogia da Semivirtualidade: caracterizando a modalidade semipresencial. In: ENCONTRO NACIONAL DE DIDÁTICA E PRÁTICA DE ENSINO, 17., 2014, Fortaleza. Anais... Fortaleza: UECE, 2014.

PMI. Um guia do conhecimento em gerenciamento de projetos: Guia PMBOK. 5. ed. Pennsylvania: Project Management Institute, Inc., 2013.

ROCHA, F. G.; SABINO, R. F.; ACIPRESTE, R. H. L. A Metodologia Scrum como mobilizadora da prática pedagógica: um olhar sobre a Engenharia de Software. In: FÓRUM DE EDUCAÇÃO EM ENGENHARIA DE SOFTWARE (CBSOFT), 8., 2015, Belo Horizonte. Anais...Belo Horizonte: SBC, 2015. p. 13-23.

RODRIGUES, C. O. M.; LIMA, V. M. F. A Bitácora como ferramenta de ensinoaprendizagem na arquitetura. Revista Projetar: Projeto e Percepção do Ambiente, Natal, v. 2, n. 3, p. 47-60, dez. 2017.

SANTOS, M. C. C.; BARRA, S. R.. O Projeto Integrador como ferramenta de construção de habilidades e competências no ensino de engenharia e tecnologia. In: CONGRESSO BRASILEIRO DE EDUCAÇÃO EM ENGENHARIA (COBENGE), 11., 2012, Belém. Anais... Belém: Abenge, 2012.

SCHON, D. A. Educando o profissional reflexivo. Porto Alegre: Artes Médicas, 2000.

SCHWABER, K.; SUTHERLAND, J. Scrum guide 2016. [S.1]: Scrum.Org, 2016. Disponível em:

<http://www.scrumguides.org/docs/scrumguide/v1/Scrum-Guide-Portuguese-BR.pdf > . Acesso em: 31 out. 2017.

SEVERO, C. E. P. Os efeitos educativos de práticas pedagógicas interdisciplinares baseadas em projetos na educação profissional e tecnológica. Interdisc., São Paulo, n. 12, p. 32-47, abr. 2018.

SOMMERVILLE, I. Engenharia de Software. 9. ed. São Paulo: Pearson Prentice Hall, 2011. 


\section{\#tear}

SOUSA, B. M. P. et al. Avaliação energética predial do Bloco I do Centro Universitário de Patos de Minas. Revista CENAR, Patos de Minas, v. 3, n. 3, 2017.

WAZLAWICK, R. S. Metodologia de pesquisa para ciência da computação. 2. ed. rev. e atual. Rio de Janeiro: Campus; Elsevier, 2014. 